\title{
“MORRITO", UNA ATALAYA CON ARTE RUPESTRE EN LA FRONTERA ENTRE ARGENTINA Y BOLIVIA
}

\author{
Alicia A.Fernández Distel \\ Centro de Estudios Indígenas y Coloniales, Universidad nacional de Jujuy, Otero \\ 262, 4600 S.S. de Jujuy, fernandezalicia@imagine.com.ar
}

Presentado: 03/03/2008 - Aceptado: 19/03/2008

\section{Resumen}

Argentina, en su límite con Bolivia, es rica en arte rupestre. El sitio que acá se describirá está en el altiplano por el que pasaba el Camino Incaico y el Camino Real al Perú. Es zona de trueque (sal, coca, etc.) y punto donde hay pueblos alfareros.

"Morrito" es un cerrito (de 8 metros de altura) de areniscas ferruginosas ordovícicas. Se yergue junto a una laguna de verano. Los indicios arqueológicos en superficie son de pueblos tardíos.

El arte rupestre grabado está reunido en la parte más alta y en una continuación alargada de la misma roca, en la llanura. Se llamó Morrito I a lo que está en el cerrito, cerca de una "apacheta" ( mojón ritual actual) y Morrito II a lo que está en lo plano.

Se identificaron 11 grupos de arte en Morrito I y 2 grupos en Morrito II. El tema es el de los camélidos en rebaños, con hombres con túnicas triangulares y aros en las manos; son figuras que rondan los $8 \mathrm{~cm}$ de alto. Los motivos geométricos son escasos. No hay referencias a lo europeo. La pátina es intensa y el grabado es desprolijo. El arte rupestre pertenecería a la extendida "cultura Chicha" que llegó hasta época española; los grabados "Chichas" de Morrito serían ligeramente anteriores a la llegada de los incas en el año 1440.

Palabras clave: petrograbados, apacheta, cultura Chicha.

\begin{abstract}
Argentina, on its border with Bolivia is rich in rock art. The place wich is being described is in the "altiplano" where the Incan and the spanish royal roads, went through. It is a trade region (salt, coca, meat, etc...) and a spot with villages of potters.

"Morrito" is a small hill ( 8 meters high) of ordovician ferruginous sandstones. It raises beside a summer lagoon. The archaeological evidence on the surface is from late peoples.

The engraving rock art is on the highest part and on an extended portion of the same rock on the plain. Morrito I was called to what is on the hill, near a current ceremonial cairn ("Apacheta").Morrito II, to what is on the plain.

11 art groups were identified, on Morrito I, and 2 on Morito II. The topic is camelids in herds, with men with triangular tunics and rings on their hands; they are figures of $8 \mathrm{~cm}$ high. The geometrical patterns are scarce. There is no reference to the europeans. The patina is intense and the engraving is careless.Rock art would belong to the extended bolivian" Chicha culture" which went to the spanish period.But the "Chichas" engravings of the site would be just before the arrival of the Incas around the year 1440 .
\end{abstract}

Keywords: engraved rock art, cairn, chicha culture 


\section{Introducción}

El mapa arqueológico de la frontera norte de Jujuy, República Argentina, es rico en expresiones de arte rupestre. Las que caen en el Departamento Yavi gozan la ventaja de usar como soporte las famosas areniscas terciarias rojas y su iconografía es abigarrada con amplio predominio de curvas. Las que caen en el Departamento Santa Catalina aprovechan afloramientos de pizarras ordovícicas más difíciles de tallar y menos vistosas en su resultado final. Su iconografía deja de lado la geometría para entrar a representar al hombre y al camélido.

Tal cantidad de arte rupestre habla de una franja altiplánica intensamente poblada sectada por caminos que servían al intercambio de productos, fundamentalmente la sal ( Methfessel y Methfessel 1997).

Demás está decir que la franja es cortada por el famoso camino troncal incaico, a lo largo del cual también se dan tupidas manifestaciones de arte rupestre pintado y grabado ( Fernández Distel et al 2004).

Acá se describirá una estación de arte rupestre inédita sobre el camino automotor que une Santa Catalina con Piscuno (Jujuy), a metros de los hitos fronterizos.

\section{Morro Chico o "Morrito"}

Los topónimos con calificativos de color, tamaño, calidad del accidente geográfico son numerosos en Jujuy. A veces aparece el calificativo y otras veces puede ser directamente reemplazado por un diminutivo como es el caso del accidente que se está tratando. Como Morro Chico figura en el Diccionario Geográfico de Jujuy (Paleari 1986:254). Aquí se explica que está a $5 \mathrm{~km}$ al este de Cieneguillas, a $22 \mathrm{~km}$ al sudeste de Santa Catalina, a $3600 \mathrm{~m}$ sobre el nivel del mar y atravesado por la Ruta Provincial 64.

El agua que se reúne en esas planicies es captada por un arroyo que también lleva el nombre de Morro Chico y que pertenece a la cuenca centrípeta de la laguna de Pozuelos. El sitio arqueológico muestra una laguna temporaria de agua pluvial, sin desagüe.

\section{La Finca Santa Catalina}

La Finca Santa Catalina fue muy preciada por los españoles por su llanura apta para las tareas pastoriles sobre todo porque varios acuíferos y lagunas aseguraban que la cubierta vegetal no se extinga. Esta Finca no entró a las posesiones de los marqueses de Yavi, pues otro español la pretendía: el Maestre de Campo Isidro Figueroa. Hacia 1778 este realista la poseía ( Cardozo 2000:110). Pocos años después la adquiere la familia Aramayo (Cardozo 2000:110 y Teruel 2005) la que, centrada en Tupiza (Bolivia), tenía importantes intereses mineros. Un siglo detenta la familia Aramayo la finca indivisa En 1889 comienzan las ventas de parcelas a los arrendatarios y hoy se puede decir que Piscuno ( y el sitio Morrito) es terreno privado de un poblador puneño que no es consciente que dentro de sus predios hay bienes históricos y arqueológicos ( los que acá se describen). 


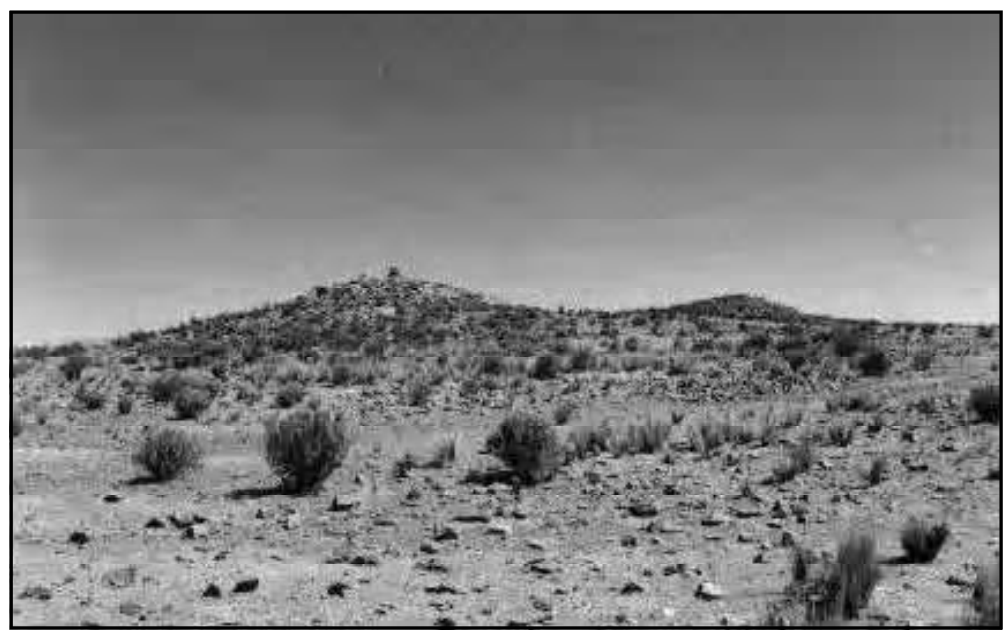

Figura 1. Morrito I.

La zona es atendida desde la Comisión Municipal de Cieneguillas. Tuvo mayor importancia antes de que se construyera el camino carretero que une rectamente Cieneguillas con Santa Catalina. Luego de esta construcción, el paso por Morrito y Piscuno dejó de ser obligatorio.

\section{El sitio. Sus contenidos}

Su atractivo debió ser siempre la presencia de un espejo de aguas reunido en época de lluvias y que hacia el final del invierno se deseca. Tomadas las coordenadas al borde de la laguna se tendría para Morrito: 21 grados 56' 24" Lat. Sur y 66 grados $00^{\prime} 28^{\prime \prime}$ Long Oeste.

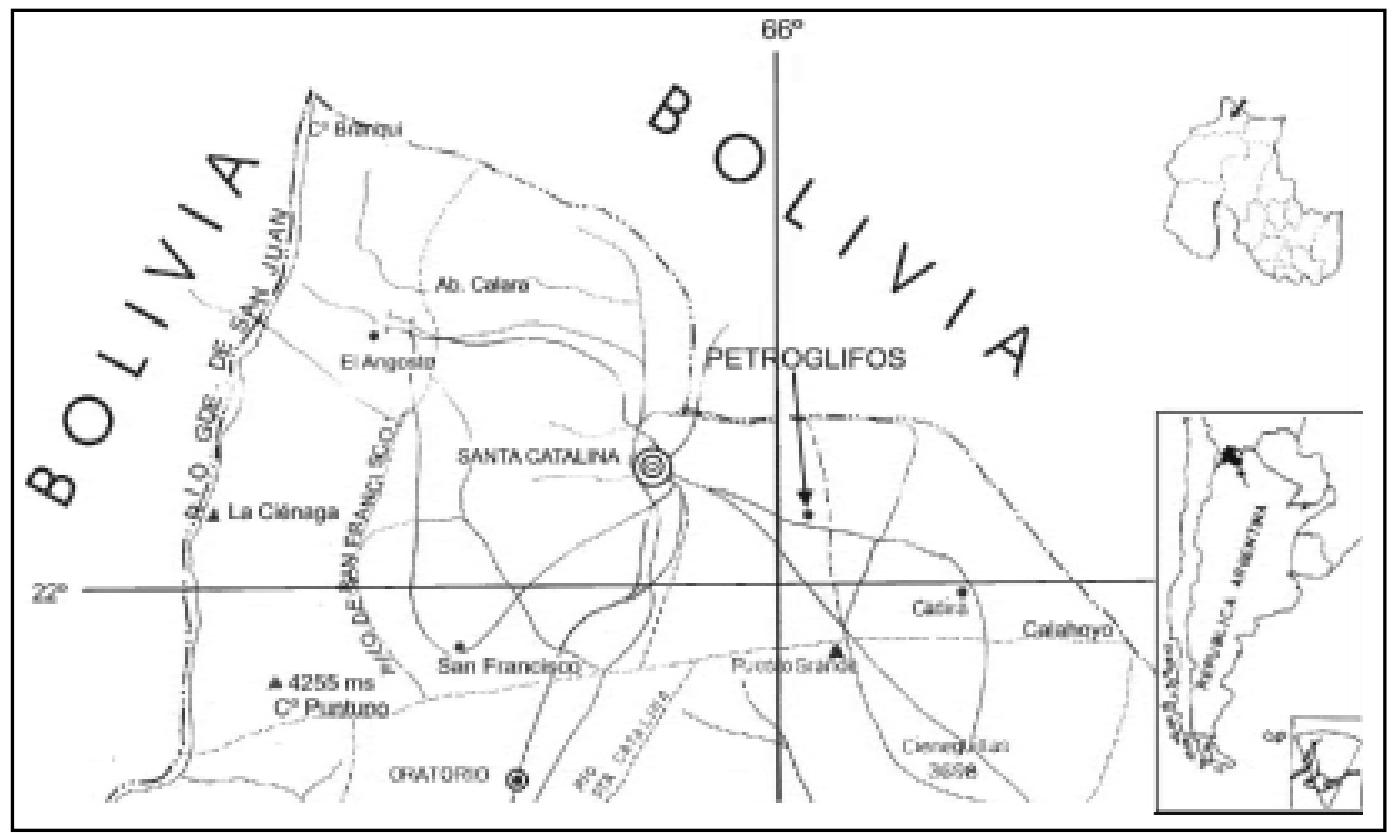

Figura 2. Ubicación de los sitios reseñados. 
Se denominó Morrito I (fig. 1) al afloramiento más alto que muestra una apacheta-mojón actual, y Morrito II (fig.4) al afloramiento longitudinal que une esta prominencia con el camino automotor a Santa Catalina. La roca del afloramiento es arenisca ferruginosa ordovícica, color gris, con vetas de cuarzo. En los dos sectores hay movimientos recientes de bloques, hechos por obreros (¿municipales?). Aunque también la búsqueda aurífera motivada por la presencia de cuarzo, ha hecho que se realicen cateos drásticos e irreversibles en los afloramientos.

La excavación arqueológica es imposible en el lugar por falta de acumulaciones sedimentarios.

Además de los denominados Morrito I y II caracterizados por su arte rupestre grabado, debe contarse con un sector denominable " Morrito templete", está en la ladera del promontorio, en la suave caída hacia la laguna. Es donde se realizaron los hallazgos cerámicos y líticos de superficie. Para describir el arte rupestre de Morrito I se siguieron los lineamientos de Lagiglia (1994:24) identificando grupos y describiéndolos de derecha a izquierda y tomando varios otros datos de relación. En Morrito I se identificaron 11 grupos, algunos

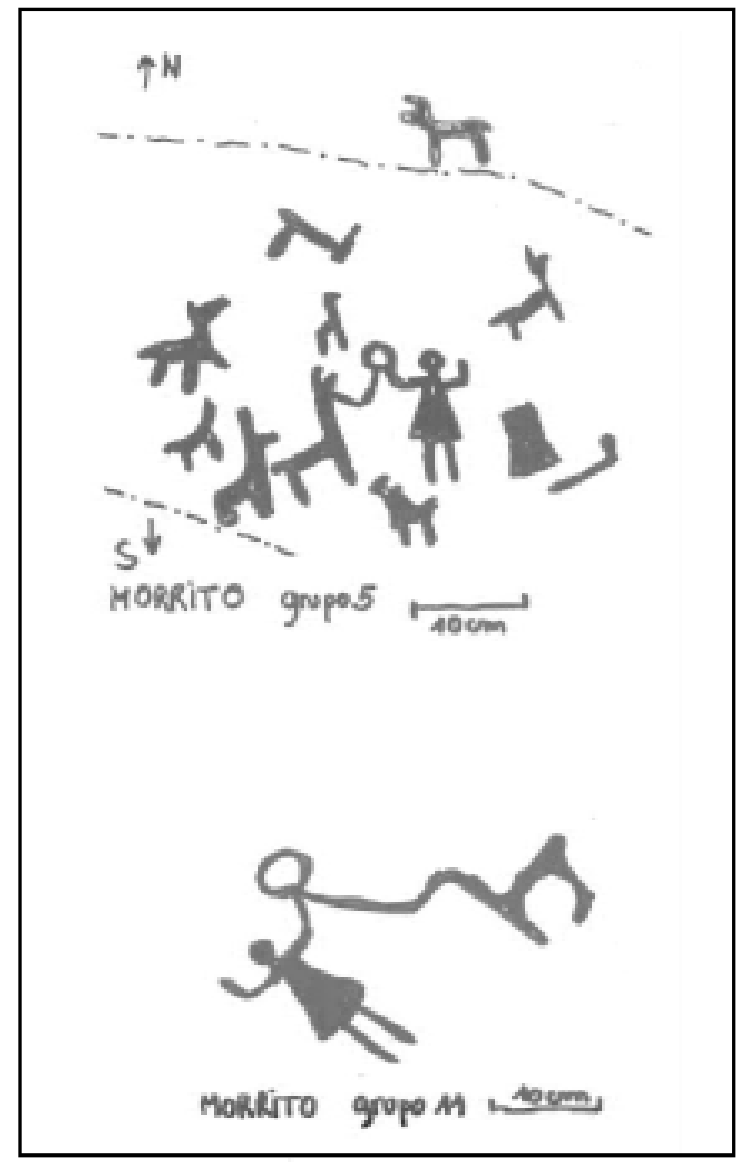

Figura 3. 


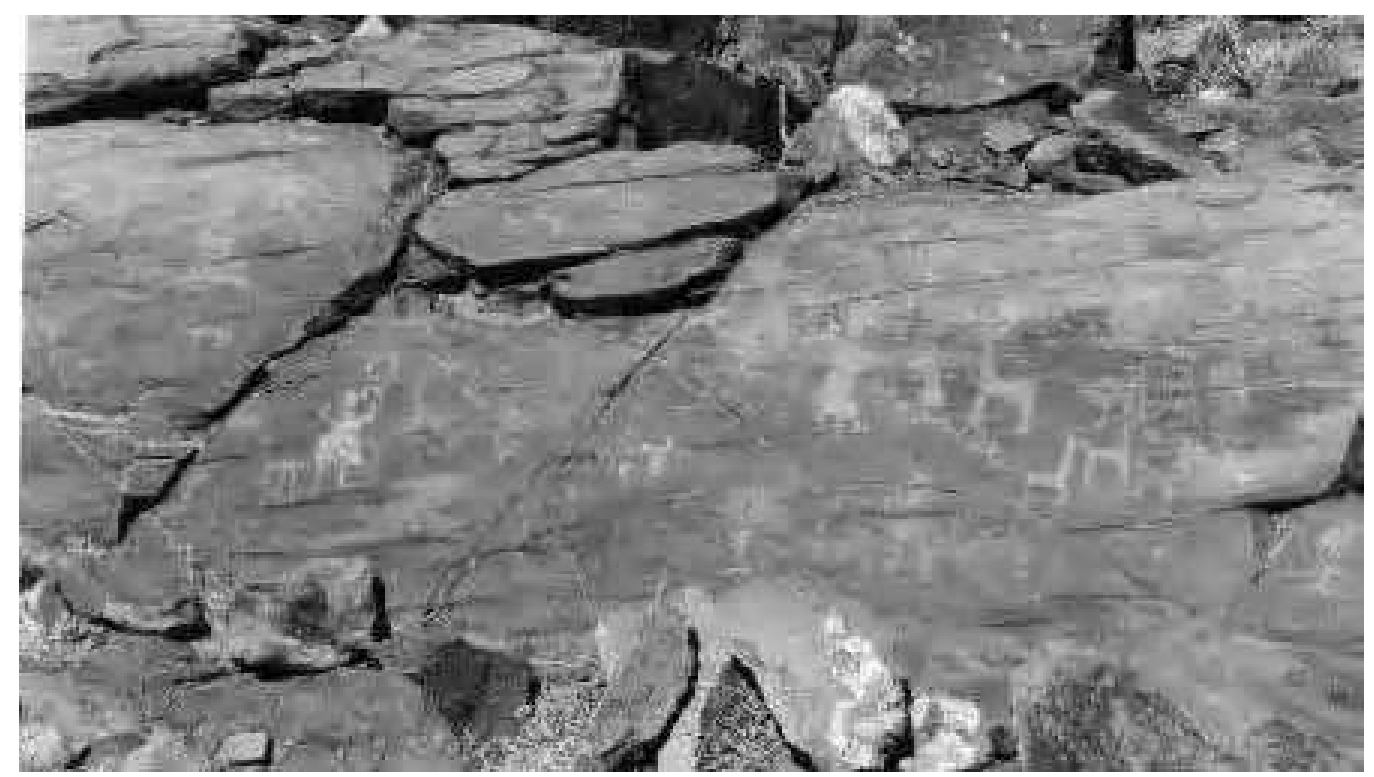

Figura 4. Morrito II.

llenos de motivos otros con un único dibujo. Dos grupos están en afloramientos fijos, los restantes en piedras desencajadas, algunas directamente con los dibujos invertidos por cambio de posición original. En el cuadro que se adjunta se observa el drástico e irreversible desencacajamiento de las piedras soportes. Los grupos 1,5,6,10 y 11 (fig.3) contienen escenas de antropomorfos con falda corta triangular y con objetos redondos en la mano. En combinación con camélidos muy simples, sin datos de pechera, carga, marcas. Todo esto falta, viéndose un perfil elemental del animal con dos patas.

El grupo 8 muestra dos soles y el grupo 9 dos circunferencias. Por lo demás los motivos geométricos escasean.

Morrito II muestra una escena con humanos (¿mujeres?) de uncu triangular con redondeles en la mano y camélidos. También hay un grupo aislado, escaso en motivos.

El tamaño de un panel no alterado y armónico va de los 40 a los $50 \mathrm{~cm}$ de lado, de modo que el arte rupestre de Morrito puede ser visto como " pequeño" con camélidos que nunca sobrepasan los $10 \mathrm{~cm}$ de altura.

La técnica es el picado de superficies planas, llenas, con muy poca profundidad y con los límites indefinidos, muy erráticos. La pátina es intensa.

En "Morrito Templete" se ven las ruinas de lo que pudo ser un oratorio de hace 100 años, con filas de piedra demarcado un área de procesión y desplazamiento de imágenes y fieles. Aquí se realizaron los hallazgos líticos y de cerámica en superficie. Los tiestos están marcadamente pisoteados. 


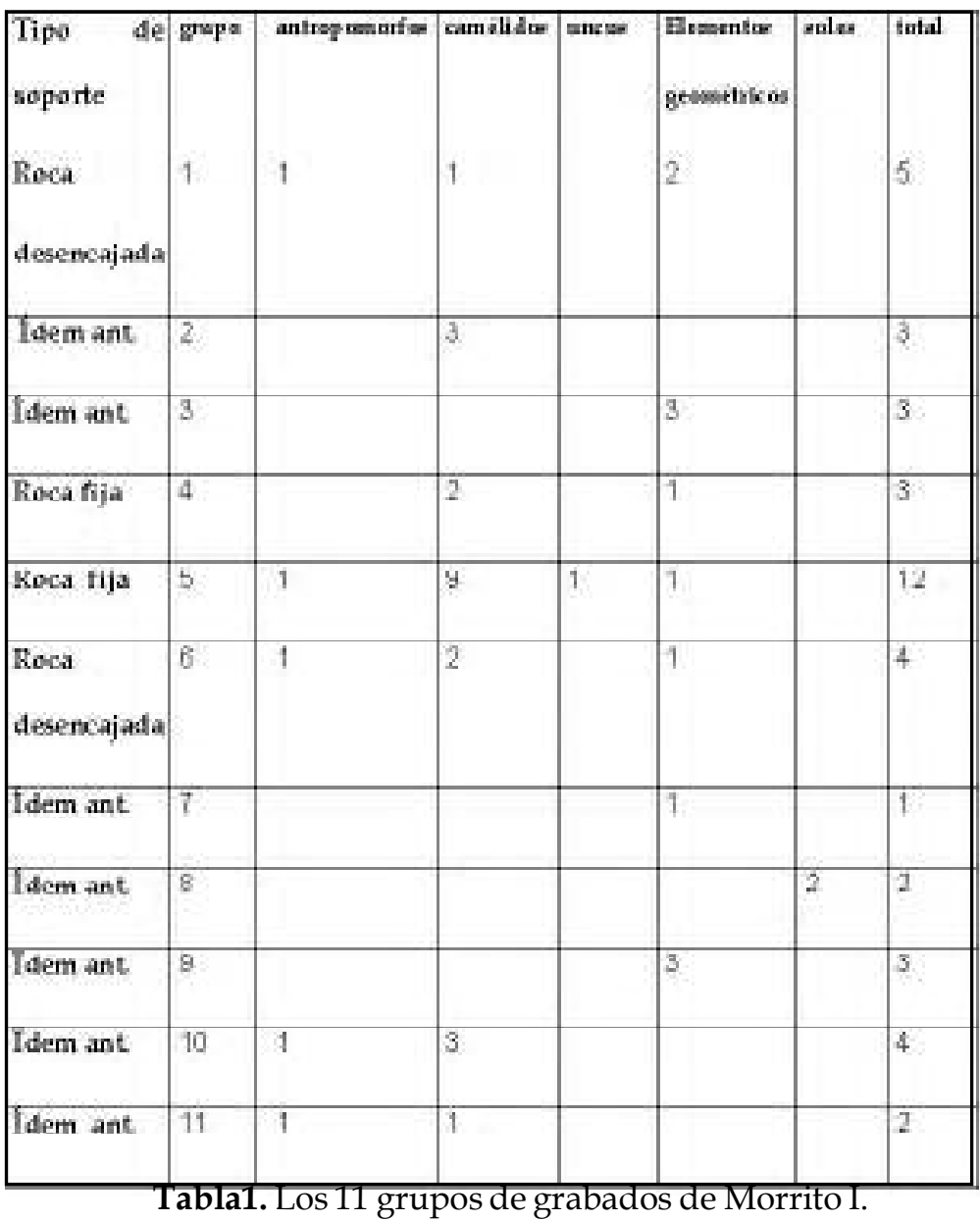

Se recogieron 40 elementos cerámicos de los cuales 39 son de cerámica roja lisa con antiplástico de granos blancos o grises (esquisto molido). A veces ambas caras están alisadas, en otros casos el interior tiene engobe también color rojo. Hay bordes y asas de vasijas evertidas cocinadas mayoritariamente de modo oxidante.

Sólo dos tiestos son de cerámica realizada con torno y vidriada en el interior (pucos). El vidriado se obtendría del molido finísimo de escorias de metales mezclados ( Ots y Gorris 2007:409). Se aplicaba en solución antes de la cocción sobre la pieza bien seca y evitaba la persistencia de poros. El color de la pieza cuyos tiestos se hallaron en Morrito es 10 YR 5/4 de la escala Munsell es decir marrón amarillento.

En piedra se halló un fragmento de piedra pómez redondeado ( posible adminículo para la terminación de la cerámica) y lascas de sílice y cuarzo en número bajo ( 3 en total). 


\section{Morrito en relación con los polos de cultura de Casira-Calahoyo}

Casira adquirió renombre más bien hacia la época independiente ( siglos XIX y XX) como enclave de pueblos ceramistas, coyas dedicados a la confección en cantidades más que artesanales de ollas, pucos, macetas, etc. Objetos que en su comercialización llegaban hasta Buenos Aires.

Casira tiene connotaciones etnohistóricas. Se tornó célebre por haber sido citado por Cronistas ( Del Pino Manrique 1787, Juan Lozano Machuca 1581, Juan de Matienzo 1567) como tambo en el Quapqñan o camino Inca por el Alto Perú, luego utilizado por los españoles. Casira figura en mapas coloniales muy antiguos (Saignes 1982-83). Hoy aquí también hay radicados ceramistas, quienes se extienden hasta el mismo pueblo de Piscuno.

Frente a la irradiación de estos polos culturales, al que se sumaría un tercero que sería Santa Catalina con sus famosos " cementerios" prehispánicos ( Fernández Distel 2002), poco protagonismo le quedaría a Morrito. Más aun, habría que pensar que a su mojón o apacheta concurrirían gentes ceramistas de Casira y Calahoyo a realizar algunos rituales y que la alfarería en superficie es actual.

La aplicación de barniz antes de la cocción o vidriado de la cerámica está documentada en Mendoza para el siglo XIX (Ots y Gorriz 2007:204). En Bolivia puede tal vez remontarse a algo antes cuando del auge minero resultaron variedad de escorias, tornos en "alfares" formales al modelo hispánico y "hornos de vasija" aptos para una cocción delicada donde las piezas vidriadas no se pegasen y otros detalles.

Pero el arte rupestre de Morrito es carente de motivos europeos (letras, números, jinetes)y se relaciona muy bien con el de Santa Catalina y Yoscaba que también tiene un carácter conservativo (Fernández Distel 2002) ligado a las escenas de ganadería de llamas. Sería el arte rupestre de los pastores y caravaneros chichas-lipes extendido también en los bordes de la Laguna de Pozuelos (Mamaní 1997). La cultura Chicha, es típica del sur de Bolivia, yendo desde época preinca a la llegada de los españoles. La dureza de la roca fue un limitante en la plástica de estos pueblos. Pero también parece que se siguieron patrones transaltiplánicos del Horizonte Tardío e Inca, pues los motivos son idénticos a los de Santa Bárbara I, grupo A, en el Loa, Chile (Berenguer et al 2007:46).

Sobre todo en el modo de hacer las llamas, insistir en escenas que las incorporen, prescindir de los geométricos decorativos (como es típico de la Cultura de los Yavi para la misma época y compartiendo un hábitat en la frontera argentino- boliviana a la altura de la actual ciudad de La Quiaca).

Como pasa en otros sitios de Jujuy o en los petroglifos antes mencionados, este tipo de camélido muy elemental muchas veces aparece con un jinete en el lomo, antropomorfo portando un sombrero, lo que coloca a los grabados más allá del Horizonte Agroalfarero Tardío e Inca, llevándolos a la época de contacto con el español. La falta de estos reciclados de camélidos en Morrito, permite ubicarlos antes del año 1550 .

Que se hable de un "atalaya" o sitio de visual extendida sobre la llanura altiplánica es una inferencia producto de la lógica actual y pretérita. El afloramiento no ofrece refugio ni a 
caminantes ni a rebaños, Pero juega el útil papel de ser punto elevado y con buena visual. Que allí se haya realizado una apacheta apoya esta inferencia.

Evidentemente la sacralidad pretérita del sitio se ha perdido completamente y la "profanación" con fines utilitarios (la construcción) del afloramiento aquí llamado atalaya trae una pronta destrucción del arte. Si a ello se suma la progresiva desecación de la laguna adyacente, la concurrencia al lugar se ve reforzada por la existencia de "buena piedra" para la municipalidad, olvidando los valores ínsitos de "Morrito".

\section{Bibliografía}

Berenguer J, G. Cabello y D. Artigas.

2007. Tras la pista de petroglifos vecinales al Quapqñan en el Alto Loa, Norte de Chile. Chungara 39 (1): 29-49, Arica.

Cardozo, E.

2000. Historia Jujeña, Batalla de Quera. San Salvador de Jujuy: Talleres Gráficos Zissi.

Fernández Distel, A.

2002. Santa Catalina, un centro cultural prehispánico con arte rupestre en la frontera argentinoboliviana. En Arte Rupestre y región, Centro de Estudios Indígenas y Coloniales, Ed., pp. 6979. S.S. de Jujuy. Universidad Nacional de Jujuy.

Fernández Distel, A., A. Díaz y L.Califano

2004. Arte Rupestre y caminos prehispánicos: los pueblos de Rinconadillas y Casabindo en la puna de Jujuy. En: Iconografía prehispánica de Jujuy: una visión desde la arqueología, A. A.

Fernández Distel Ed., pp.109-119,. Buenos Aires: Editorial Dunken.

Lagiglia, $\mathrm{H}$.

1994. Libreta del arqueólogo. San Rafael: Instituto de Ciencias Naturales de San Rafael.

Mamaní,H.

1997.Ms. Organización espacial de las sociedades agroalfareras prehispánicas en el sector Occidental de la cuenca de Pozuelos (dep. Rinconada, Jujuy). Tesis de Licenciatura en Antropología, Universidad Nacional de Jujuy, Jujuy.

Methfessel C. y M. Methfessel.

Ms. La ruta de la sal a lo largo a lo largo del Río San Juan del Oro y Tarija. Presentación a las Jornadas Internacionales de Arte Rupestre, Salta.

Ots M. y N. Goriz

2007. Aportes a la caracterización tecno-tipológica de la cerámica colonial del área fundacional de la ciudad de Mendoza. En Arqueología Argentina en los inicios de un nuevo siglo, F. Oliva, N. de Grandis y J. Rodríguez compiladores, pp. 403-412. tomo 1. Rosario: Laborde Editor. 
Paleari, A.

1986.Diccionario Geográfico de la Provincia de Jujuy. Buenos Aires: Instituto Geográfico Militar.

Saignes, T.

1982-83. Acerca de un mapa colonial inédito del Sur Boliviano. Arte y Arqueología, 89,pp.169-182, La Paz.

Teruel, A.

2005. Estructuras agrarias comparadas: la puna argentina y el sur boliviano a comienzos del siglo XX. Mundo agrario, revista de estudios rurales 11:8-23. La Plata: Instituto de Estudios Agrarios. 